\title{
Does active rheumatoid arthritis affect intestinal iron absorption?
}

\author{
H-P BENN, ${ }^{1}$ J DREWS ${ }^{1}$ G RANDZIO,$^{2} \mathrm{~J} \mathrm{M} \mathrm{JENSEN}^{2}$ AND H LÖFFLER ${ }^{1}$ \\ From the ${ }^{1}$ Second Department of Internal Medicine, University of Kiel, FRG; and the ${ }^{2}$ Radiological Clinic of $f^{0}$ \\ the University of Kiel, FRG
}

SUMMARY One of the causes of anaemia in rheumatoid arthritis is thought to be defective iron absorption. In this study the ${ }^{59} \mathrm{Fe}$ absorption in patients with active rheumatoid arthritis is $\frac{\rho}{\circ}$ measured and correlated with the results for bone marrow iron stores (and in some cases with the. iron stores in the terminal duodenum), which were assessed simultaneously with semiquantitative ${ }_{-}^{N}$ methods, and with the serum ferritin concentration. In 11 patients with rheumatoid arthritis and $\overrightarrow{+}$ increased bone marrow iron stores, iron absorption was decreased. In five patients it was normalo and in three further patients, whose bone marrow iron stores were depleted, iron absorption wasmaximally increased. According to the results both intestinal malabsorption and defective iron ${ }_{\mathbb{D}}^{T}$ absorption can be excluded as causes.

Key words: anaemia, whole body counting.

One of the most common extra-articular features of active rheumatoid arthritis (RA) is anaemia, which is generally normocytic, normochromic, and at times slightly hypochromic. Its pathogenesis is complex and by no means clear. ${ }^{12}$ In addition, depending on the index of activity, patients with RA show a decreased serum iron concentration, decreased serum transferrin, and increased serum ferritin. Serum ferritin generally yields higher than normal baseline values in patients suffering from RA. ${ }^{34}$ Abnormal ferrokinetic parameters ${ }^{5-7}$ and heterotopic quantitative iron stores have been demonstrated in synovial tissue ${ }^{8}$ and lymph nodes. ${ }^{9}$

To what extent 'defective' iron absorption is causally related to the anaemia, the altered iron status, and the heterotopic pattern of iron stores associated with RA has been studied by various authors. ${ }^{10}$ The studies published to date, however, are either based on indirect or semiquantitative methods $^{11} 12$ or appear to be inconclusive. ${ }^{13}{ }^{14}$ Their results do not agree.

We have therefore measured whole body ${ }^{59} \mathrm{Fe}$ retention in 19 patients suffering from RA with varying bone marrow iron stores.

Accepted for publication 17 July 1987.

Correspondence to Dr H P Benn, II Medizinische Klinik der Universität Kiel, Metzstrasse 53/57, D 2300 Kiel, FRG.

\section{Patients and methods}

PATIENTS

In 19 patients (12 female, 7 male, mean age $54 \stackrel{\circ}{\mathrm{O}}$ years, range 24-73) with active rheumatoid arthritis, all of whom fulfilled the criteria of the American Rheumatism Association, intestinal iron absorption was measured before starting treatment with gold, D-penicillamine or azathioprine, and corticosteroids. The duration of disease before the diag- $\frac{0}{2}$ nostic absorption test and the other laboratory: assays ranged from six months to several years.

Before our investigations 13 patients had received only non-steroidal antirheumatic agents, which were $₹$ given in the form of suppositories on the day of the 0 diagnostic test-four hours after administration of the nucleide at the earliest. One patient was given o $40 \mathrm{mg}$ prednisolone daily several days before and during the test period because symptoms could not $\sigma$ be relieved with other measures. Five patients had N previously received gold or azathioprine, or both. N No patient had been given oral or parenteral iron therapy for a period of several months before our investigations. In no case did we find residual? endothelial siderosis in the bone marrow. This specific heterotopic iron compartment in human bone marrow is commonly detected after intra-ō venous administration of colloidal iron. The typical迎 uniform granules representing non-ferritin iron in 
lysosomes of endothelial cells disappear only one to three years after iron therapy has been stopped. ${ }^{15}$

\section{CONTROLS}

The controls were six patients with iron deficiency anaemia who did not suffer from arthritis and 20 healthy persons with normal iron intake (11 female, nine male); two further patients had iron overload owing to repeated transfusions. None of the controls received any drug.

TEST AND SOLUTION

We used the diagnostic ${ }^{59} \mathrm{Fe}$ absorption test ${ }^{16}$ using $10 \mu \mathrm{mol}(0.56 \mathrm{mg}){ }^{59} \mathrm{Fe}^{++}$labelled ferrous chloride with $100 \mu \mathrm{mol}(17.6 \mathrm{mg}) \mathrm{L}$-ascorbate in $0.001 \mathrm{~N} \mathrm{HCl}$ administered orally with $100 \mathrm{ml}$ water (distilled three times). The activity of the solution was relatively high at $0 \cdot 19-0.37 \mathrm{MBq}$ because not only was ${ }^{59} \mathrm{Fe}$ absorption measured with a whole body counter but also external organ measurement and articular ${ }^{59} \mathrm{Fe}$ deposits were recorded with variable detectors (unpublished data). Whole body activity is generally counted 14 days after oral administration of the nucleide and the iron absorption recorded as a percentage of the total administered dose of ${ }^{59} \mathrm{Fe}$. This procedure is based on the assumption that unabsorbed ${ }^{59} \mathrm{Fe}$ has been completely eliminated by then. Recently we have begun to realise that intestinal iron absorption is a more complicated process than hitherto thought and includes such components as mucosal uptake, mucosal transfer, and mucosal elimination ${ }^{17} 18$ and continues over a long period of time.

The amount of ingested iron which after transient mucosal uptake is again actively secreted into the intestinal lumen can be measured by whole body counting and is referred to as postabsorption excretion (PAE). According to Björn-Rasmussen PAE can be expressed mathematically as the proportion of nucleide excreted from the 10th day after oral administration of radioiron until no more than basal losses can be measured $\left(\mathrm{PAE}_{10}\right){ }^{19}$ We were interested in measuring the regulatory capacity in all of its components and chose the time period from the seventh to the 14th day after nucleide administration for the PAE counts, though this is not strictly speaking representative.

Under these conditions the following standards hold for the diagnostic ${ }^{59} \mathrm{Fe}$ absorption test: $<10 \%=$ suspected $\mathrm{Fe}$ malabsorption, acquired iron overload; $10-45 \%(24 \%$ in men; $32 \%$ in menstruating women)=iron absorption of healthy subjects; $50-100 \%=$ depleted iron stores; idiopathic haemochromatosis, iron loading anaemias. ${ }^{2021}$

WHOLE BODY COUNTER

A whole body counter is a large volume radio-

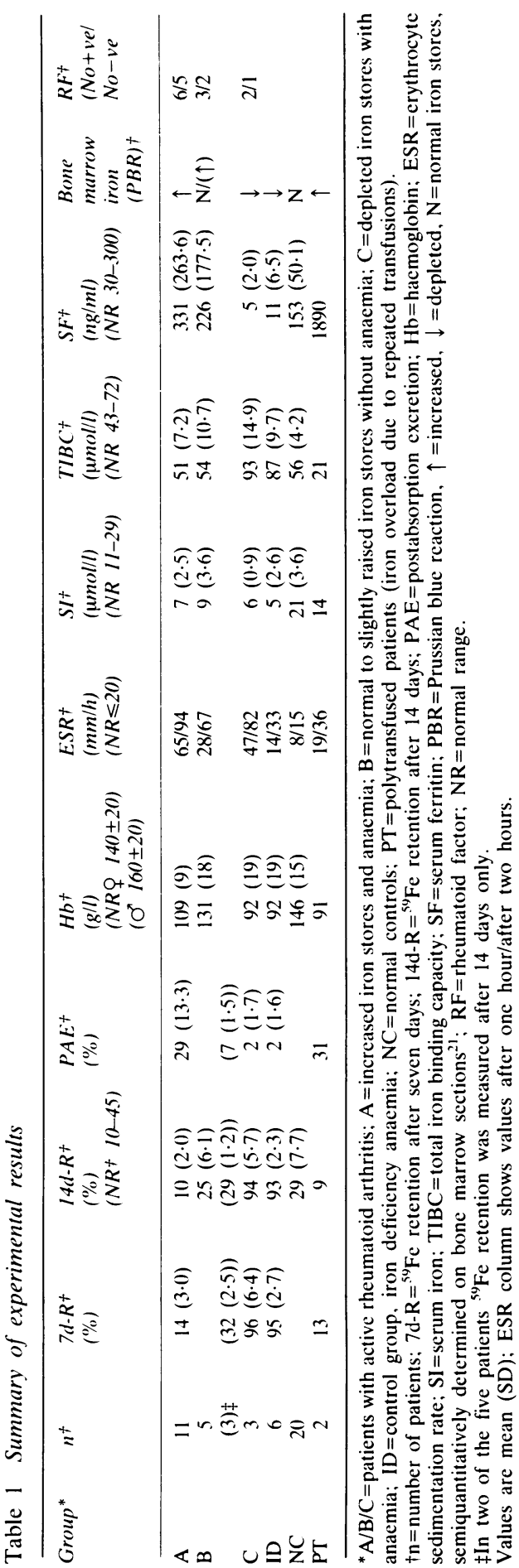


activity detector (Frieseke and Hoepfner) with four scintillator blocks ( $\mathrm{NaI}$ crystals, 5 inches each) that can be moved in three dimensions by means of motors and can be fitted to the individual body geometry of the recumbent patient in a reproducible manner. Two scintillator blocks are located above and two below the patient.

A D DITIONAL DATA

The laboratory data shown in Table 1, including the haematological and morphological parameters, were obtained by routine laboratory methods. Serum ferritin was measured with the two site solid phase assay of the sandwich type (RIA-Gnost ferritin, Behring-Werke AG). The results were not corrected to the WHO standard.

\section{S T A T IS T I CS}

Student's $t$ test was used for statistical evaluation. 2223

\section{Results}

In 19 patients (seven male, 12 female) who were

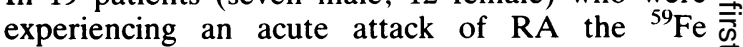
absorption rates ranged from $7 \%$ to $99 \%$, i.e., their absorption rates ranged from normal to maximum. No significant correlation could be established between the individual absorption rates and the severity of the anaemia $(p=0.001)$.

Group A (Table 1) consisted of anaemic RA के patients with raised serum ferritin values and $\overrightarrow{0}$ accordingly large bone marrow iron stores. The $\overrightarrow{\vec{H}}$ mean iron absorption rate in this group of $10 \stackrel{\mathrm{N}}{\mathrm{\omega}}$ (SD 2)\% was below normal (see also Fig. 1).

In group $C$ (Table 1) all patients were also frankly anaemic (mean $\mathrm{Hb} 92 \mathrm{~g} / \mathrm{l}$ ). The serum ferritin values, averaging $5(2) \mu \mathrm{g} / \mathrm{l}$, indicate iron deficiency. ? According to the cytological results the bone $\overrightarrow{\vec{A}}$ marrow iron stores were depleted. As expected,

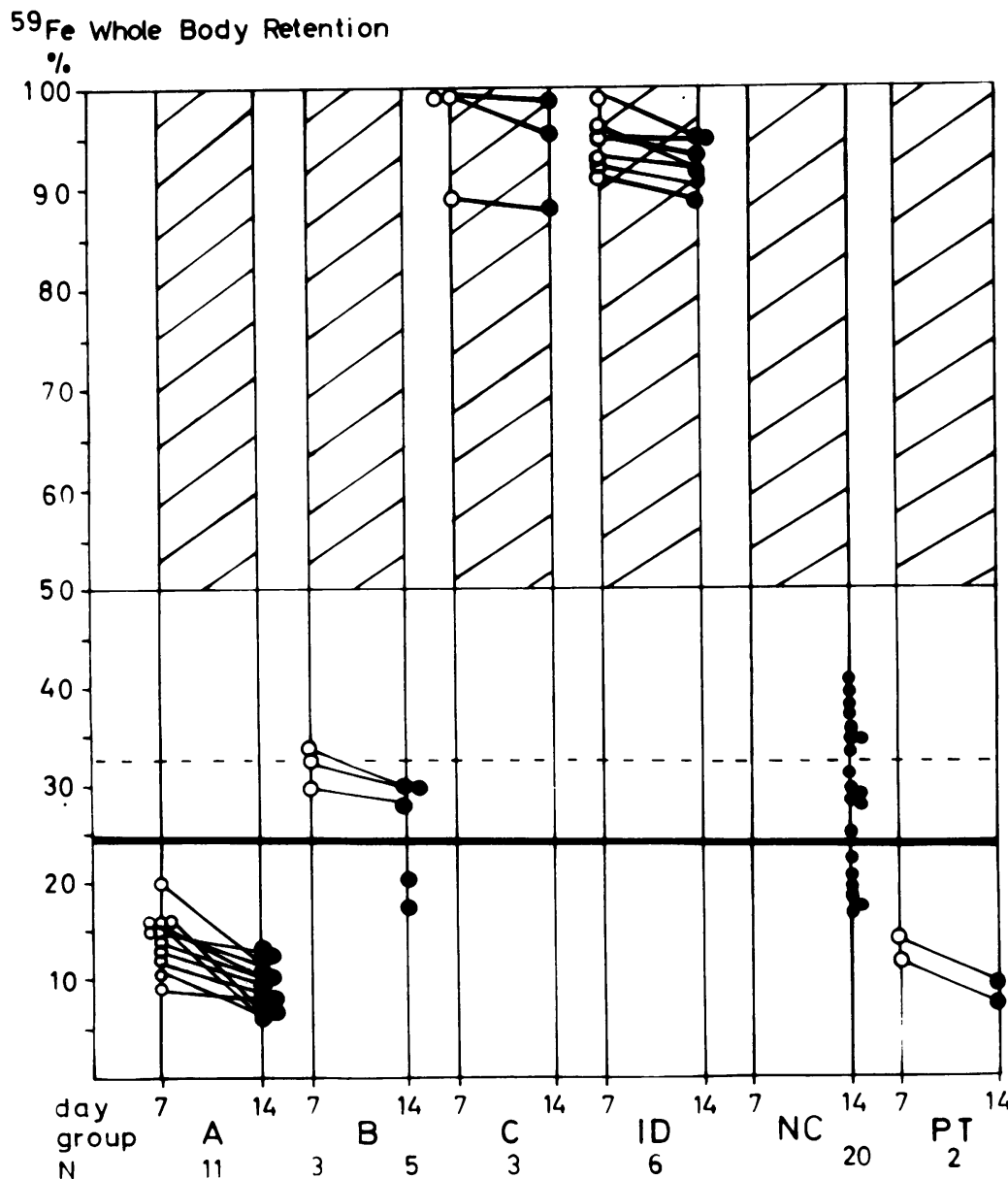

Fig. $1{ }^{59} \mathrm{Fe}$ whole body retention in various groups. $\bigcirc={ }^{59} \mathrm{Fe}$ seven day retention; $={ }^{59} \mathrm{Fe} 14$ day retention; - = percentage ${ }^{59} \mathrm{Fe}$ 14 day retention in healthy men, mean $(S D)=24(10) \%$;

$---1=$ percentage ${ }^{59} \mathrm{Fe} 14 \mathrm{da}$ retention in menstruating women, mean $(S D)=32(10) \%$; hatched 응 area $={ }^{59} \mathrm{Fe}$ absorption range $(R)$ in patients with depleted iron stores with and without anaemia $=50 \%$ $\leq R \leq 100 \%{ }^{20}$ Groups $A, B, C$, $I D, N C, P T$ are defined in Table $1 \stackrel{\text {. }}{ }$ $N=$ number of patients. 
iron absorption was maximally increased to $94(5 \cdot 7) \%$ (Table 1 and Fig. 1).

In group B (Table 1) the patients had a normal red blood count, normal serum ferritin values, and normal to slightly raised bone marrow iron stores. In these patients normal iron absorption rates were accordingly measured. A significant difference in this parameter was found between groups A and B $(p=0 \cdot 0001)$.

In some patients in groups $\mathrm{A}, \mathrm{B}$, and $\mathrm{C}$ (Table 1) and in all patients in the group ID gastroduodenoscopy was performed for diagnostic purposes.

Biopsies of three patients in group A (increased bone marrow iron stores) indicated the presence of large amounts of iron positive material in the duodenal villi. Otherwise this was found only in two patients with an iron overload due to transfusions. In two patients from each of the groups $\mathrm{B}$ and $\mathrm{C}$ and in all controls with iron deficiency anaemia (group ID) no iron could be demonstrated in the duodenal villi.

PAE of ${ }^{59} \mathrm{Fe}$ was higher in group $\mathrm{A}$ (mean $(\mathrm{SD})=29(13.3) \%)$ than in groups $\mathrm{B}$ and $\mathrm{C}$ (Table 1). Thus in group $\mathrm{A}$ a considerable amount of temporarily retained iron must have been actively eliminated, whereas this did not occur in patients with RA who also had deficient bone marrow iron stores and in patients with simple iron deficiency anaemia (groups $\mathrm{C}$ and ID, both mean $\mathrm{PAE}=2 \%$ ). Our patients with an iron overload due to transfusions had a PAE of $31 \%$; this corresponds to the mean PAE of group A (29 (13.3)\%, Table 1).

Radioiron absorption of our normal controls (group NC) with a mean (SD) of 29 (7.7)\% correlated well with previously published data in this field. ${ }^{20}$ Ranges of serum iron and total iron binding capacity values corresponded with the iron status and inflammatory activity of our patients. Intestinal iron absorption rates do not correlate with seroreactions; seropositive and seronegative RA patients did not behave differently in regard to iron retention (Table 1 ).

\section{Discussion}

Rheumatoid arthritis is almost always associated with massive heterotopic iron deposits in the synovial tissue and the lymph nodes and, as long as no iron is lost owing to bleeding, correlates also with adequate to excessive bone marrow iron stores (Drews, unpublished data). Simultaneously the serum ferritin values are moderately to greatly increased and, depending on the disease activity, anaemia is observed, with typical haemoglobin values of between 90 and $120 \mathrm{~g} / \mathrm{l}$.

Various authors have published studies on iron absorption in patients with RA with divergent results.

Jeffrey et al calculated the iron absorption rates of 15 patients with RA from the difference between the amount of orally administered ${ }^{59} \mathrm{Fe}$ and the amount of ${ }^{59} \mathrm{Fe}$ that was eliminated with the faeces over a period of 10 days. ${ }^{11}$ The investigation showed an increase in iron absorption by a factor of almost three in patients with RA compared with normal subjects. In this study, however, the iron status of the patients was not sufficiently well defined.

Weinstein studied only the early plasma iron kinetics of orally administered ${ }^{59} \mathrm{Fe}$ in six patients with RA whose iron status was not classified in detail. $^{12}$ He did not find significant differences between these patients and six normal controls.

Boddy and Will measured the ${ }^{59} \mathrm{Fe}$ whole body retention rate of 15 patients with RA by whole body monitoring. ${ }^{13}$ The authors administered ${ }^{59} \mathrm{Fe}$ labelled iron in the ferric state, which is not readily bioavailable, and in a dose of $5 \mathrm{mg}$, an amount which is known to lead to a dose dependent decrease in the percentage of iron absorption. ${ }^{20}$ Under these conditions it is impossible to achieve a broad range of up to $100 \%$ retention of the orally administered nucleide and the distinction between persons with depleted iron stores and normosiderotic or hypersiderotic stores is less clear.

Boddy and Will did not find any significant difference in iron absorption between RA patients with normochromic, normocytic anaemia and their control group. Patients with hypochromic anaemia, to whom the authors imputed iron deficiency without assessment of their exact iron status, showed an average iron absorption of only $50 \%$ of that of a group of subjects with iron deficiency anaemia not suffering from RA.

In principle it is possible with the diagnostic ${ }^{59} \mathrm{Fe}$ absorption test, which we used in all cases, to measure whole body retention scores up to $100 \%$ precisely and reproducibly with a whole body counter 14 days after nucleide administration, because of the very small oral dose of $10 \mu \mathrm{mol}{ }^{59} \mathrm{Fe}$ labelled ferrous chloride. If standardised test principles (see 'Patients and methods') are strictly adhered to it can be considered that the amount of iron absorbed depends on the available iron stores $^{21}$; very few exceptions are known and these can be identified by the iron status of the blood and by histochemical investigations of bone marrow and Fe stores.

The question at issue is whether intestinal iron absorption of patients suffering from RA represents one exception that proves the rule.

Our results (Table 1 and Fig. 1) show that active $\mathrm{RA}$ is not accompanied by a defect in iron absorp- 
tion, nor is such a defect responsible for the anaemia that is often associated with the disease. On the contrary, even in active RA there is an effective Fe absorption mechanism that compensates for iron deficiency by increasing the absorption rate. In cases of iron surplus, which is reliably reflected by the amount of iron confined to bone marrow macrophages, iron retention becomes protectively depressed. Accordingly patients with RA in group B fall within the 14 day iron retention normal range because during remission the anaemia is compensated for by use of the previously increased bone marrow iron stores (group B: mean (SD) $25(6 \cdot 1) \%$ ). From our results we infer that the degree of depression of iron absorption is related to the degree of severity of the anaemia in the patients with RA as long as the anaemia is exclusively related to the inflammatory process. This is always the case when utilisable iron is available in the bone marrow. If there is a negative iron balance, and if this is reflected as a depletion of iron stores, the organism adjusts iron absorption upwards to the highest physiologically possible degree, even during active disease.

The way the organism adjusts intestinal iron absorption rate to homoeostatic requirements is not completely understood. ${ }^{14}$ Nevertheless, convincing positive correlation can be established between body iron stores and histochemically assessed iron content of mucosal macrophages in the upper intestine,$^{24} 25$ which favours the assumption that both iron compartments are connected in parallel. Thus the absorptive gut would be informed about actual iron requirements of the body and measurable postabsorption excretion of ingested iron would gain a morphological basis.

The parameter referred to here as PAE should not be regarded as established. It needs to be confirmed in a large group of subjects. We have used it in an 'abbreviated' form, because the $\mathrm{PAE}_{10}$ defined by Björn-Rasmussen ${ }^{19}$ sometimes cannot be determined for certain until five weeks or more after nucleide administration. ${ }^{18} 25$ As this would have postponed the beginning of therapy for an unacceptably long period the particular parameter PAE $_{10}$ (see 'Patients and methods') could not be established for our patients. Our measurements of PAE values are based on reports by Boender et al, ${ }^{26}$ Boender and Verloop, ${ }^{27}$ and Powell et al, ${ }^{28}$ who all agree that orally administered non-absorbable radioisotopes are completely eliminated by one week after ingestion. Thus the difference in ${ }^{59} \mathrm{Fe}$ whole body retention measured between the seventh and the 14th day is an expression of a postabsorption phenomenon that corresponds to excretory processes involving mucosal iron in the sense of Björn-Rasmussen. ${ }^{19}$ It must be presumed that a comparatively depressed ${ }^{59} \mathrm{Fe}$ absorption rat is associated with a high PAE and consequently irom ought to be detected histochemically in the muco of the small intestine. Our investigations of du denal biopsy specimens indicate that only in R patients with increased bone marrow iron stores ca stainable iron be demonstrated in the duodenal wa RA patients with normal or depleted iron stores hol no mucosal iron. This agrees with studies of Astaldi et al, who did not find any iron positive villi 은 normosiderotic and hyposiderotic subjects in this section of the intestine, whereas hypersiderote subjects did show mucosal iron. ${ }^{29}$ We found in the duodenal biopsy specimens of hypersiderotic $\mathrm{R} / \mathrm{A}$ patients that lysosomal iron accumulations seen under the electron microscope and verified by means of $x$ ray microanalysis are confined to perivascular and interepithelial macrophages in the tips of the villi of the terminal duodenum (un. published results).

Occult intestinal bleeding is unlikely to influence PAE values of patients in groups $\mathrm{A}, \mathrm{B}, \mathrm{NC}$, and PT as simultaneous Haemoccult testing during measurement of ${ }^{59} \mathrm{Fe}$ absorption showed no positive reactions in stools. Some patients in group $\mathrm{C}$. group ID had endoscopically verified slight infes tinal bleeding; this could increase PAE. Medmin PAE (2\%), however, corresponds well with $\overrightarrow{P A}$ values of iron deficient patients without bleedin reported elsewhere. ${ }^{17}$ Possibly, intestinal irritatio occurred in iron deficient RA patients (group owing to the use of non-steroidal drugs. The amour of drug induced blood loss, however, assessed by the ${ }^{51} \mathrm{Cr}$ method hardly exceeds $3 \mathrm{ml}$ a day, ${ }^{30}$ whic represents the detection limit of whole body counting over short time intervals. ${ }^{18}$ Thus our PA data evaluated between day 7 and day 14 post absorption would not be affected.

Supported by the Verein zur Förderung der Erforschung un Bekämpfung rheumatischer Erkrankungen, D 2357 Bad Brarstedt, FRG.

\section{References}

1 Harvey A R, Clarke B J, Chui D H K, Kean W F, Buchanan W W. Anemia associated with rheumatoid disease. Arthrif Rheum 1983; 26: 28-34.

2 Reid C D L, Prouse P J, Baptista L C, Gumpel J M, Chanarin CW The mechanism of the anaemia in rheumatoid arthritis. Bry Haematol 1984; 58: 607-15.

3 Smith R J, Davis P, Thomson A B R, Wadsworth L D, Fackre F Serum ferritin levels in the anemia of rheumatoid arthritis J Rheumatol 1977; 4: 389-92.

4 Hansen T M, Hansen N E, Birgens H S, Holund B, Lorenzen $T^{7}$ Serum ferritin and the assessment of iron deficiency in rheume toid arthritis. Scand J Rheumatol 1983; 12: 353-9.

5 Samson D, Halliday D, Gumpel J M. Role of ineffecti $\frac{\rho}{\mathbb{Q}}$ 
erythropoiesis in the anaemia of rheumatoid arthritis. Ann Rheum Dis 1977; 36: 181-5.

6 Cavill I, Bentley D P. Erythropoiesis in the anaemia of rheumatoid arthritis. Br J Haematol 1982; 50: 583-90.

7 Williams R A. Samson D. Tikerpae J, Crowne H, Gumpel J M. In vitro studies of ineffective erythropoiesis in rheumatoid arthritis. Ann Rheum Dis 1982; 41: 502-7.

8 Muirden K D, Senator G B. Iron in the synovial membrane in rheumatoid arthritis and other joint diseases. Ann Rheum Dis 1968; 27: 38-48.

9 Muirden K D. Lymph node iron in rheumatoid arthritis. Ann Rheum Dis 1970; 29: 81-8.

10 Bentley D P. Anaemia and chronic disease. Clin Haematol 1982; 2: 465-79.

11 Jeffrey M R, Freundlich H F, Jackson E B. Watson D. The absorption and utilization of radioiron in rheumatoid arthritis. Clin Sci 1955; 14: 395-406.

12 Weinstein I M. A correlative study of the erythrokinetics and disturbances in iron metabolism associated with the anemia of rheumatoid arthritis. Blood 1959; 14: 950-66.

13 Boddy K. Will G. Iron absorption in rheumatoid arthritis. Ann Rheum Dis 1969; 28: 537-40.

14 Roeser H P. Iron metabolism in inflammation and malignant disease. In: Jacobs A, Worwood M, eds. Iron in biochemistry and medicine. Vol II. London: Academic Press, 1980: 605-40.

15 Hausmann K. Eisenverwertungsstörungen. In: Löhr G W Arnold H, Engelhardt R, et al, eds. Probleme der Erythrozytopoese, Granulozytopoese und des malignen Melanoms. Berlin-Heidelberg-New York: Springer, 1978: 145-61.

16 Heinrich H C. Intestinal iron absorption in man. In: Hallberg L, Harwert H G, Vanotti A, eds. Iron deficiency. 1st edn. LondonNew York: Academic Press, 1970: 213-94.

17 Marx J J M. Mucosal uptake, mucosal transfer and retention of iron, measured by whole body counting. Scand J Haematol 1979; 23: 293-302.
18 Fischer R, Benn H-P. Heinrich H C. Blutverlustmessungen mit Ganzkörperdetektoren. Medizinische Physik 1981; 9: 487-92.

19 Björn-Rasmussen E. Iron absorption: present knowledge and controversies. Lancet 1983; i: 914-6.

20 Heinrich H C. Ätiologie, Diagnostik und Dimensionierung der Therapie des Eisenmangels. Blut 1978; 21(suppl): 35-94.

21 Hausmann K, Kuse R, Sonnenberg D W, Bartels H, Heinrich H C. Inter-relations between iron stores, general factors and intestinal iron absorption. Acta Haematol (Basel) 1969; 42: 193-207.

22 Kaiser R E. Mühlbauer J A. Elementare Tests zur Beurteilung von Messdaten. 2nd edn. Zurich: Bibliographisches Institut, 1983: Vol. 774 .

23 Kreyszig E. Statistische Methoden und ihre Anwendungen. 1st edn. Göttingen: Vandenhoeck und Ruprecht, 1973.

24 Cattan D. Iron and mucosal intestinal macrophages. Lancet 1983;ii: 106.

25 Cattan D. Hémochromatose idiopathique, macrophages mononuclées et regulation de l'absorption martiale. Gastroenterol Clin Biol 1979; 3:59-66.

26 Boender C A, Mulder E, Ploem J E, de Wael J, Verloop M C. Iron absorption and retention in man. Nature 1967; 3: 1236-7.

27 Boender C A, Verloop M C. Iron absorption, iron loss and iron retention in man: studies after oral administration of a tracer dose of ${ }^{59} \mathrm{FeSO}_{4}$ and ${ }^{131} \mathrm{BaSO}_{4}$. BrJ Haematol 1969; 17:45-58.

28 Powell L W, Campbell C B, Wilson E. Intestinal mucosal uptake of iron and iron retention in idiopathic haemochromatosis as evidence for a mucosal abnormality. Gut 1970; 11: 727-31.

29 Astaldi G, Meardi G. Taverna P L, Airò R. Eisennachweis in der Dünndarmmukosa. Medizinische Klinik 1967; 62: 1339-40.

30 Jallad N S, Sanda M, Salom I L, et al. Gastrointestinal blood loss in arthritic patients receiving chronic dosing with etodolac and piroxicam. AmJ Med Sci 1986:29:272-6. 